\title{
Wind Tunnel Model Design for the Study of Plume Effects on Sonic Boom for Isolated Exhaust Nozzles
}

\author{
Ray Castner ${ }^{1}$ \\ NASA Glenn Research Center, Cleveland, Ohio, 44135, United States
}

\begin{abstract}
A low cost test capability was developed at the NASA Glenn Research Center 1- by 1-Foot Supersonic Wind Tunnel (SWT), with a goal to reduce the disturbance caused by supersonic aircraft flight over populated areas. This work focused on the shock wave structure caused by the exhaust nozzle plume. Analysis and design was performed on a new rig to test exhaust nozzle plume effects on sonic boom signature. Test capability included a baseline nozzle test article and a wind tunnel model consisting of a strut, a nosecone and an upper plenum. Analysis was performed on the external and internal aerodynamic configuration, including the shock reflections from the wind tunnel walls caused by the presence of the model nosecone. This wind tunnel model was designed to operate from Mach 1.4 to Mach 3.0 with nozzle pressure ratios from 6 to 12 and altitudes from $30,000 \mathrm{ft}$ (4.36 psia) to 50,000 ft (1.68 psia). The model design was based on a 1 in. outer diameter, was 9 in. in overall length, and was mounted in the wind tunnel on a 3/8 in. wide support strut. For test conditions at $50,000 \mathrm{ft}$ the strut was built to supply 90 psia of pressure, and to achieve 20 psia at the nozzle inlet with a maximum nozzle pressure of 52 psia. Instrumentation was developed to measure nozzle pressure ratio, and an external static pressure probe was designed to survey near field static pressure profiles at one nozzle diameter above the rig centerline. Model layout placed test nozzles between two transparent sidewalls in the $1 \times 1$ SWT for Schlieren photography and comparison to CFD analysis.
\end{abstract}

\section{Nomenclature}

$\begin{array}{ll}\text { NPR } & =\text { Nozzle Pressure Ratio }=P_{t} / P_{\infty} \\ P & =\text { Local Static Pressure, psia } \\ P_{t} & =\text { Total Pressure in Nozzle } \\ P_{\infty} & =\text { Free stream Static Pressure } \\ \Delta P & =P-P_{\infty} \\ x & =\text { axial distance from Jet Simulator nosecone, inches } \\ D & =\text { Test nozzle diameter, inches }\end{array}$

\section{Introduction}

$\mathrm{N}$ ASA has conducted research programs to reduce or eliminate the operational restrictions of supersonic aircraft over populated areas. Restrictions are due to the disturbance caused by the sonic boom, caused by the coalescence of shock waves formed off the aircraft. Recent work has been performed to reduce the magnitude of the $\mathrm{N}$-wave generated by airplane components with focus on shock waves caused by the exhaust nozzle plume.

In previous work by Putnam and Capone, ${ }^{1}$ a variety of nozzles were tested from a fully expanded Mach 1.7 nozzle to a fully expanded Mach 2.9 nozzle. Their study was conducted in a wind tunnel, where near field pressure measurements were made at one nozzle diameter away from the model. Wind tunnel conditions were Mach 2.2 at a simulated altitude of $50,000 \mathrm{ft}$. Based on this work, a baseline nozzle was selected for a two-dimensional Computational Fluid Dynamics (CFD) study.

During the CFD analysis, it was determined that over expanded and under expanded operation of the nozzle had an effect on the N-wave boom signature; and demonstrated the feasibility of reducing the magnitude of the sonic boom $\mathrm{N}$-wave by controlling the nozzle plume interaction with the nozzle boat tail shock structure, as reported by Castner. ${ }^{2}$ Results from this CFD study were used to develop a combination of CFD and wind tunnel test capability

\footnotetext{
${ }^{1}$ Aerospace Engineer, Inlet and Nozzle Branch, 21000 Brookpark Road, and AIAA Member.
} 
to validate and predict results obtained for supersonic nozzle concepts. A low cost test capability was developed at the NASA Glenn Research Center 1- by 1-Foot Supersonic Wind Tunnel (SWT). ${ }^{3}$ Analysis and design was performed for a new rig to test the exhaust nozzle plume effects on sonic boom signature. Test capability included a baseline nozzle test article and a wind tunnel model consisting of a strut, a nosecone and an upper plenum. Analysis was performed on the external and internal aerodynamic configuration.

\section{Baseline Nozzle}

A baseline nozzle was developed for initial checkout testing and qualification of the new rig in the $1 \times 1$ SWT. Figure 1 depicts the design of the Mach 2.0 baseline supersonic exhaust nozzle configuration. Previous computational and wind tunnel tests were performed on this nozzle at flight speeds of Mach 2.2 and an altitude of $50,000 \mathrm{ft}$. Figure 2 shows the larger scale wind tunnel model used by Putnam and Capone, where an $x / D$ of zero is the front of the nose cone. Near field pressure measurements were made at one nozzle diameter above the test nozzle. Data taken from Putnam's "Nozzle 6" was digitized from the report and displayed in Fig. 3. A CFD data set was obtained to match the experimental test conditions.

Pressure signatures, plotted as a ratio of $\Delta P / P_{\infty}$, were compared to the experimental data. The results from the comparison are plotted in Fig. 3.

Initial wind tunnel testing in the $1 \times 1$ SWT will collect near field pressure data for comparison to the baseline data. Upon successful validation, the new rig will be used to study novel concepts for nozzle plume effects on sonic boom.

Following baseline nozzle testing, nozzle configurations were planned based on the NASA Dryden NF-15B Lift and Nozzle Change Effects on Tail Shock research airplane. A study was also planned for supersonic nozzle pairs, with varying levels of nozzle spacing and stagger.

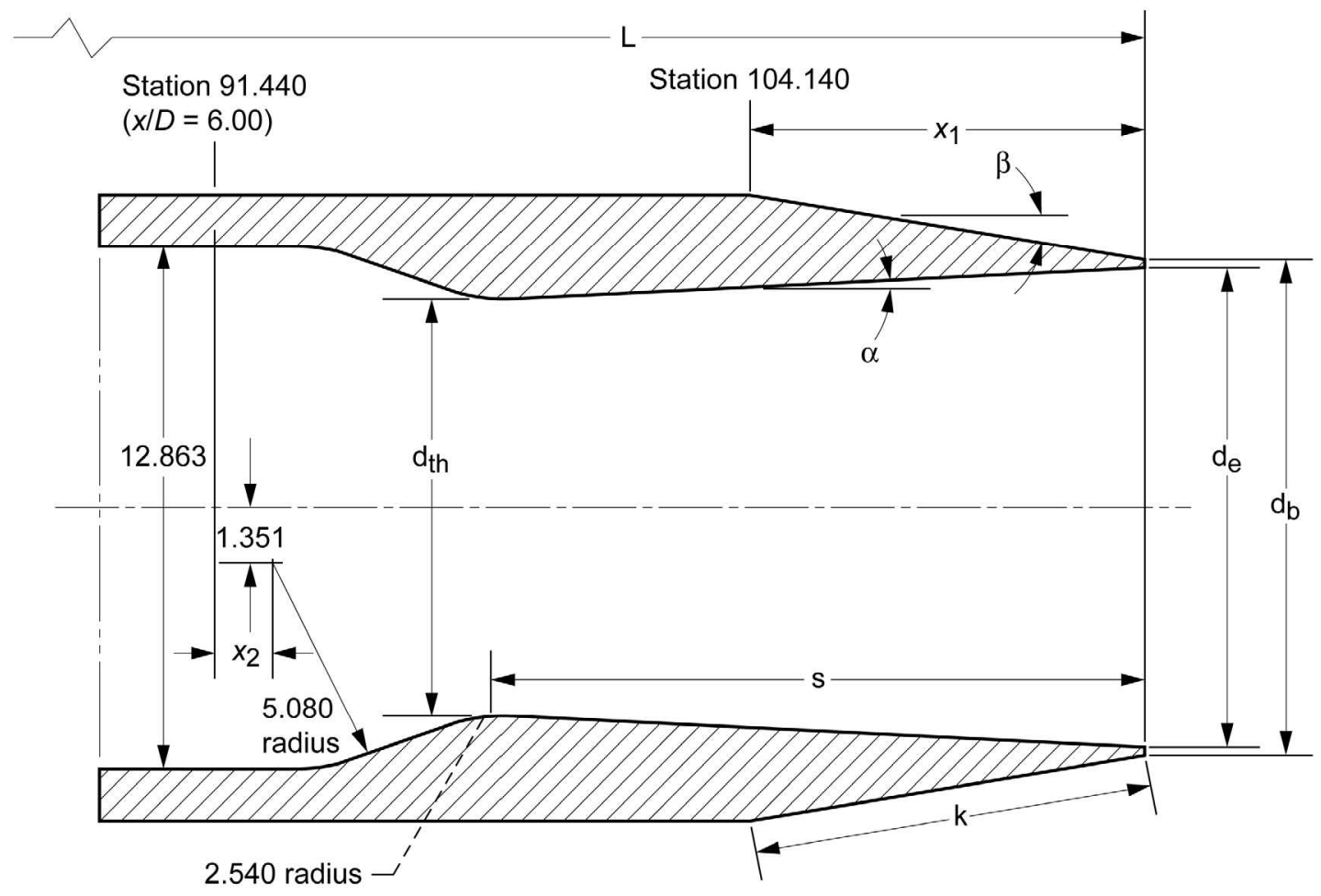

Figure 1. Baseline Nozzle. 


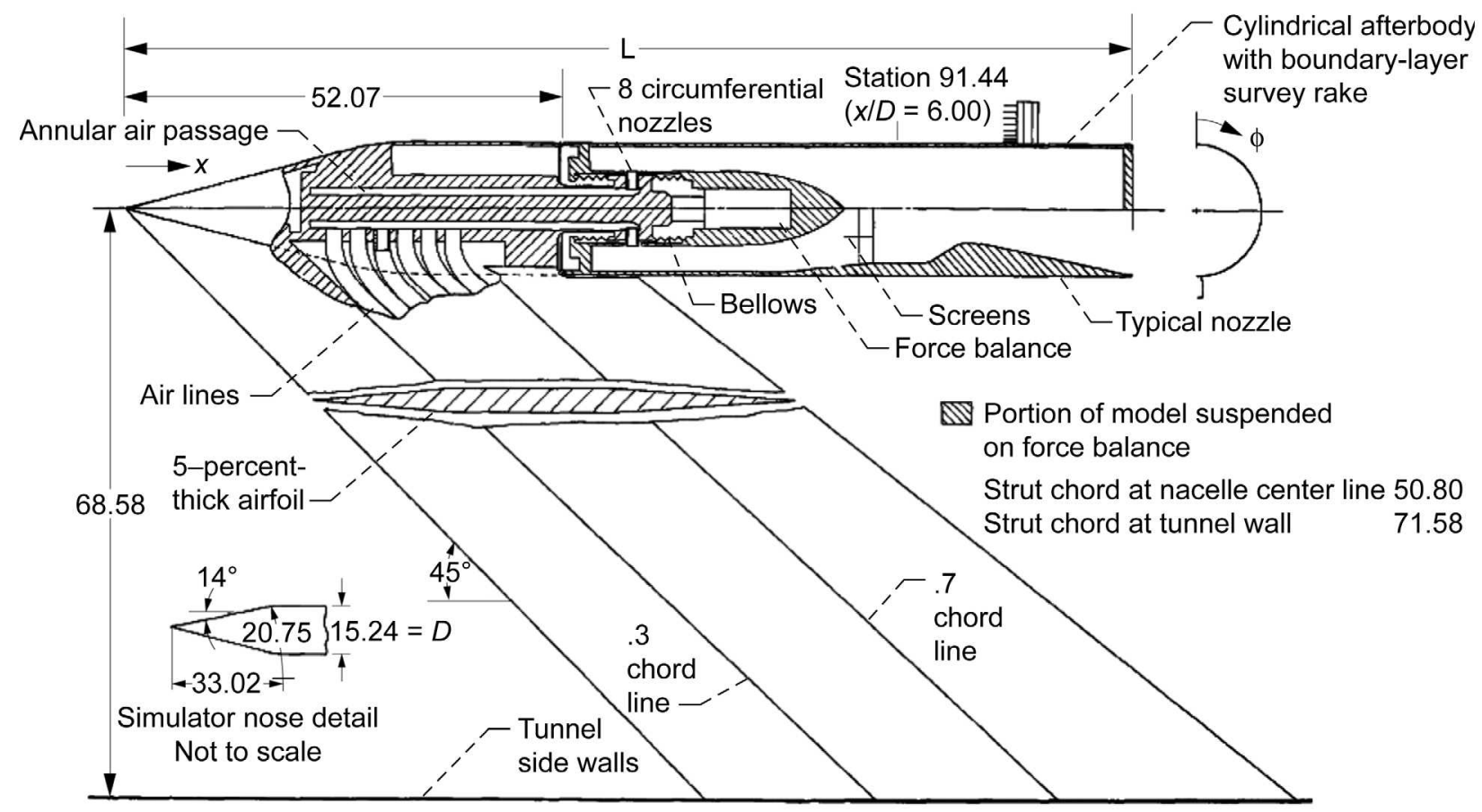

Figure 2. Exhaust Nozzle Simulator from NASA TN-D-5553.

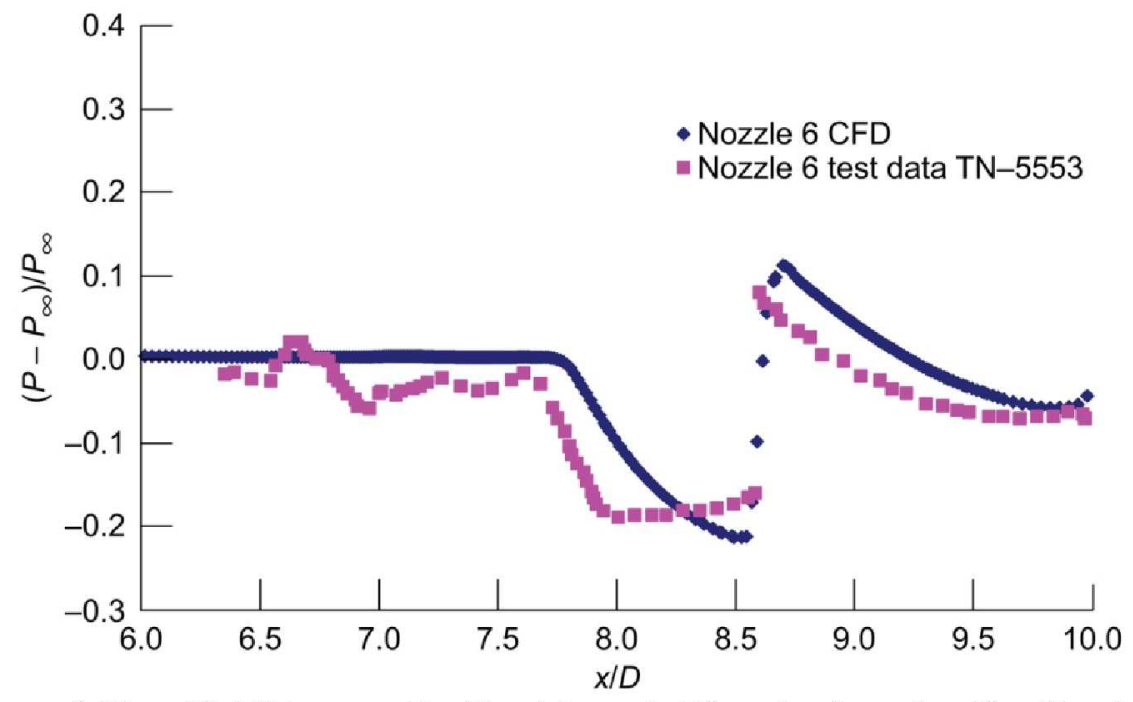

Figure 3. Near Field Pressure Profile at 1 nozzle Diameter from baseline Nozzle 6.

\section{Analysis}

Model layout included a support strut, upper plenum, nosecone, instrumentation, and nozzle mounting station, (Fig. 4). To determine the design of this wind tunnel model, a study was performed to determine model size, including both length and diameter. The objective was to have a region of 5 to 10 diameters in length downstream of the nozzle exit, uninterrupted by reflected shock waves from wind tunnel walls. Model diameters of 1, 1.5, and $2 \mathrm{in}$. were studied with spreadsheet models. Shock waves and the Prantdl-Meyer expansions were estimated from a conic nose. The reflection path from wind tunnel walls was calculated. Analysis showed that a smaller model diameter provided a longer reflection path for reflected shock waves from the tunnel walls. The longer reflection path provided a longer axial distance before the shock waves intersected the tunnel centerline. As a result, a small model 


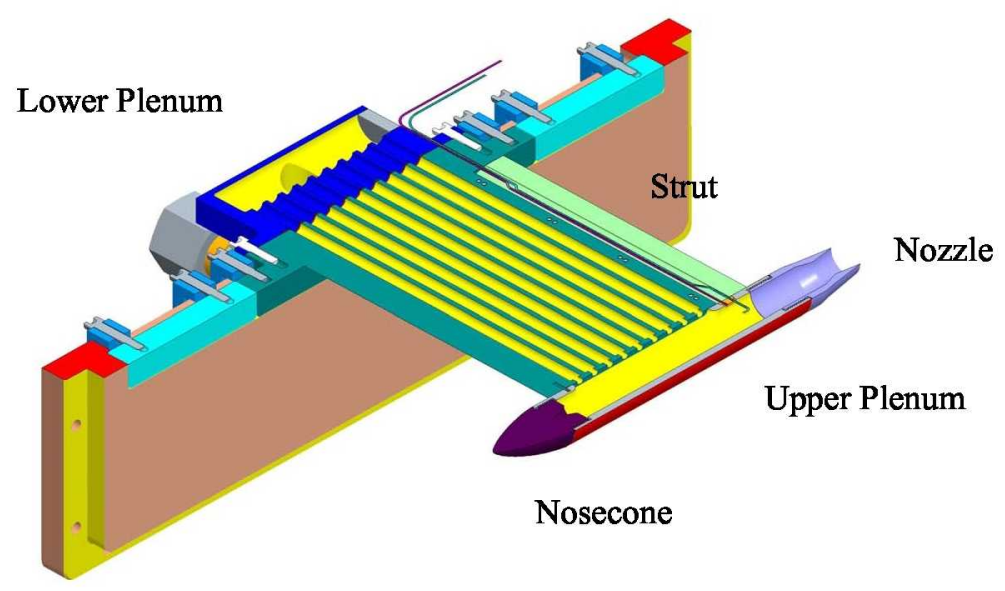

Figure 4. Wind Tunnel Model Cut-Away.

diameter of $1 \mathrm{in.}$ was selected. It was determined through analysis that a $15^{\circ}$ (half angle) nosecone and a $3 \mathrm{in}$. long plenum with a test nozzle would fit inside the reflected shock wave path, and still provide nearly 9 diameters of nozzle plume for study.

A second study was performed to determine an optimal nose cone. In literature, there was much data on lift and drag for nose cones, for example Reference 4. However, there was little published data for the shock structure propagating from these nose cones. Nose cones were studied to see if the shock strength or reflection path would change. Nose cones included a cone, a parabola, a power series, and the Von Karman nose cone, (Table 1). The length of the nose cone was also varied from a maximum of $5.7 \mathrm{in.} \mathrm{to} \mathrm{a} \mathrm{minimum} \mathrm{of} 2.85 \mathrm{in}$. in length.

Table 1. Nosecone Designs. ${ }^{6}$

\begin{tabular}{|l|c|c|c|}
\hline \multicolumn{1}{|c|}{ Nosecone } & $\begin{array}{c}\mathrm{R}, \\
\text { inch }\end{array}$ & $\begin{array}{c}\mathrm{L}, \\
\text { inches }\end{array}$ & Equation \\
\hline Long cone, 5 & 0.5 & 5.7 & $y=\frac{x R}{L}$ \\
\hline Long 3/4 parabola & 0.5 & 5.7 & $\left(\frac{2\left(\frac{x}{L}\right)-K\left(\frac{x}{L}\right)^{2}}{2-K}\right)$ \\
\hline Long 3/4 power series & 0.5 & 5.7 & Where $K=0.75$ \\
& & & $\begin{array}{c}y=R\left(\frac{x}{L}\right)^{n} \\
\text { Where } n=0.75\end{array}$ \\
\hline Long ojive & 0.5 & 5.7 & $\begin{array}{c}y=\sqrt{\rho^{2}-(L-x)^{2}}+R-\rho \\
\text { Where } \rho=\frac{R^{2}+L^{2}}{2 R}\end{array}$ \\
\hline
\end{tabular}




\begin{tabular}{|c|c|c|c|}
\hline Nosecone & $\begin{array}{l}\mathrm{R}, \\
\text { inch }\end{array}$ & $\begin{array}{c}\mathrm{L}, \\
\text { inches }\end{array}$ & Equation \\
\hline Short ojive & 0.5 & 2.85 & $\begin{array}{c}y=\sqrt{\rho^{2}-(L-x)^{2}}+R-\rho \\
\text { Where } \rho=\frac{R^{2}+L^{2}}{2 R}\end{array}$ \\
\hline Short $3 / 4$ power & 0.5 & 2.85 & $\begin{array}{c}y=R\left(\frac{x}{L}\right)^{n} \\
\text { Where } n=0.75\end{array}$ \\
\hline Short 3/4 parabola & 0.5 & 2.85 & $\begin{array}{c}y=R\left(\frac{2\left(\frac{x}{L}\right)-K\left(\frac{x}{L}\right)^{2}}{2-K}\right) \\
\text { Where } K=0.75\end{array}$ \\
\hline Short Von Karman & 0.5 & 2.85 & $\begin{array}{c}y=\frac{R \sqrt{\theta-\frac{\sin (2 \theta)}{2}}}{\sqrt{\pi}} \\
\text { Where } \theta=\arccos \left(1-\frac{2 x}{L}\right)\end{array}$ \\
\hline
\end{tabular}

Figure 5 depicts the CFD solutions for the long nosecones, $5.7 \mathrm{in}$. in length. The baseline conic nosecone with a $5^{\circ}$ half angle had open space of 8.7 nozzle diameters downstream of the nozzle exit before the shock reflection intersected the nozzle plume. Three other long nosecones had similar results, with the best nosecone being a $5^{\circ}$ cone.

Figure 6 shows the CFD solutions for the short nosecones, 2.85 in. in length. The short ojive was compared to the long ojive in Fig. 5(d). The useful space downstream of the nozzle exit increased to 9.6 nozzle diameters. Three other nosecones had similar results with 10 diameters of useful space to observe nozzle plume shock structure.

The first shock wave from the nosecone determined the location of the shock reflection. Shorter nosecones caused stronger shock reflections due to higher angles of flow turning, with a slightly shorter reflection path; however, the shorter path was offset by the shorter nosecone length. The end result was that all the short nosecones provided more space to view nozzle plume shock structure. The short Von Karman nose cone was selected because it was a low drag nose with good flow qualities.

The internal design of the model was driven by air flow requirements needed for "Nozzle 6". A scaled version of "Nozzle 6" required $0.109 \mathrm{lbm} / \mathrm{sec}$ of airflow at airspeed of Mach 2.0 and simulated altitude conditions of 50,000 ft. A narrow strut with sharp leading and trailing edges was desirable to minimize tunnel blockage and shock wave reflections in the lateral direction. The length of the strut needed to carry the airflow was the driver for the length of the upper air plenum (Fig. 4); which was desired to be near 3 in., to match the length of the upper air plenum. A $3 / 8$ in. strut thickness was selected with a 3 in. length, plus leading and trailing edges. 

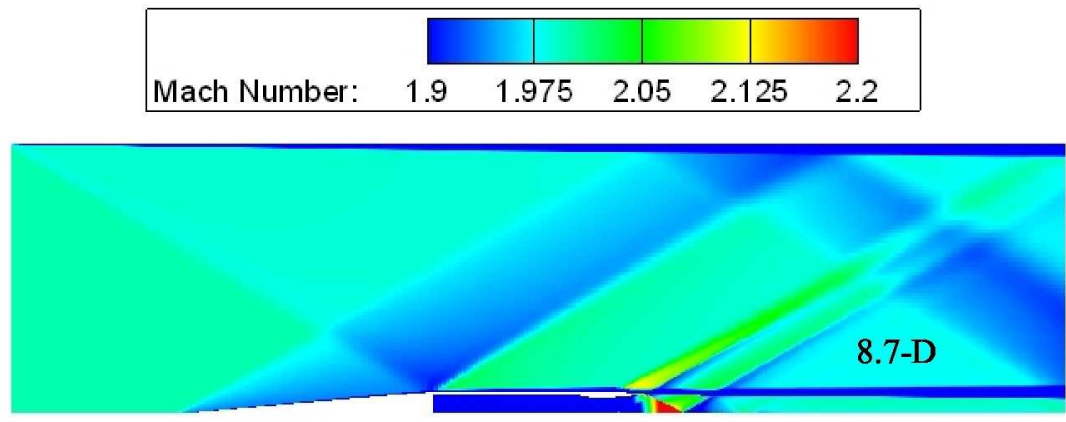

Figure 5(a). 5 deg cone: 8.7 diameter between nozzle exit and reflected shock wave at tunnel centerline.

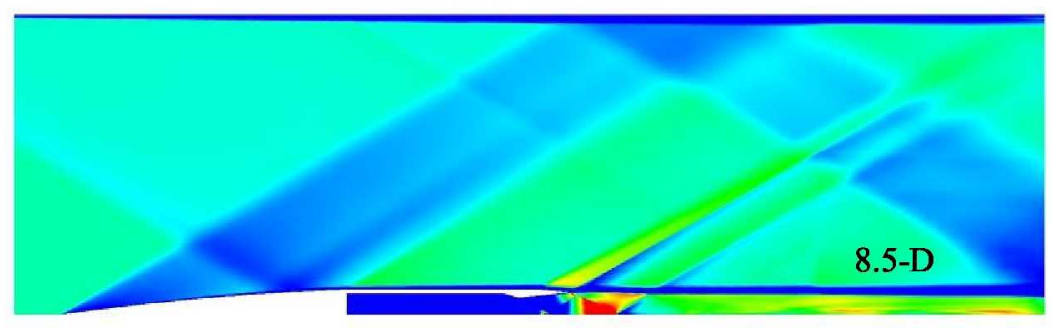

Figure 5(b). 3/4 Parabola Long: 8.5 diameter between nozzle exit and reflected shock wave at tunnel centerline.

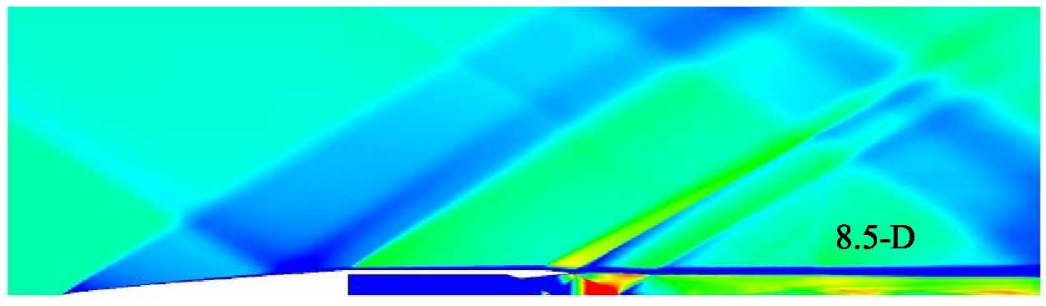

Figure 5(c). 3/4 Power Long: 8.5 diameter between nozzle exit and reflected shock wave at tunnel centerline.

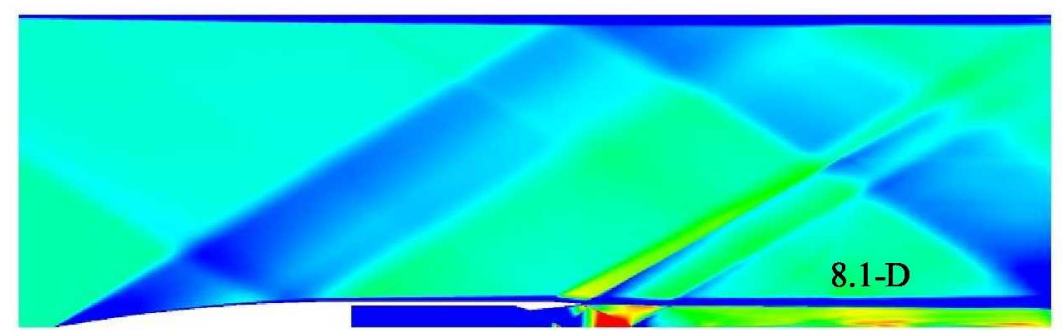

Figure 5(d). Long Ojive: 8.1 diameter between nozzle exit and reflected shock wave at tunnel centerline. 


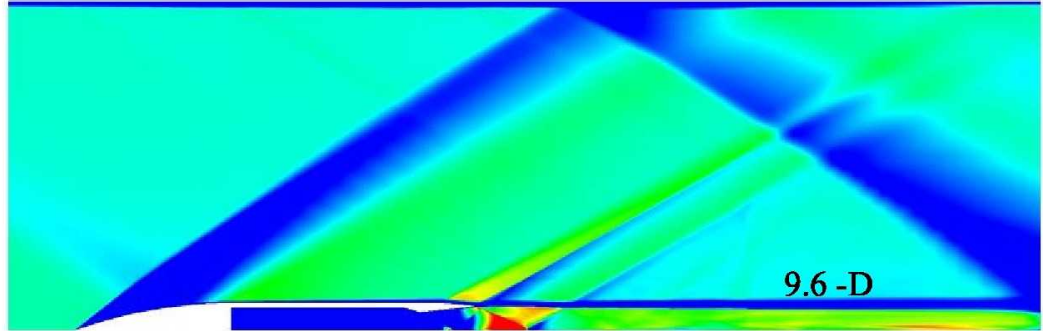

Figure 6(a). Ojive Short: 9.6 diameter between nozzle exit and reflected shock wave at tunnel centerline.

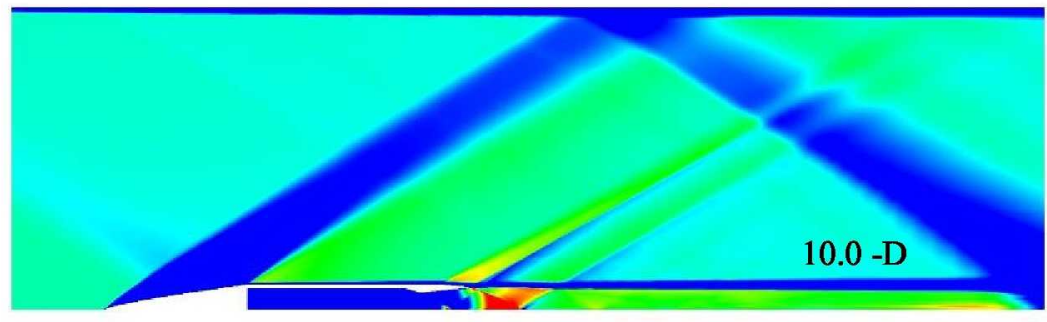

Figure 6(b). 3/4 Power Short: 10.0 diameter between nozzle exit and reflected shock wave at tunnel centerline.

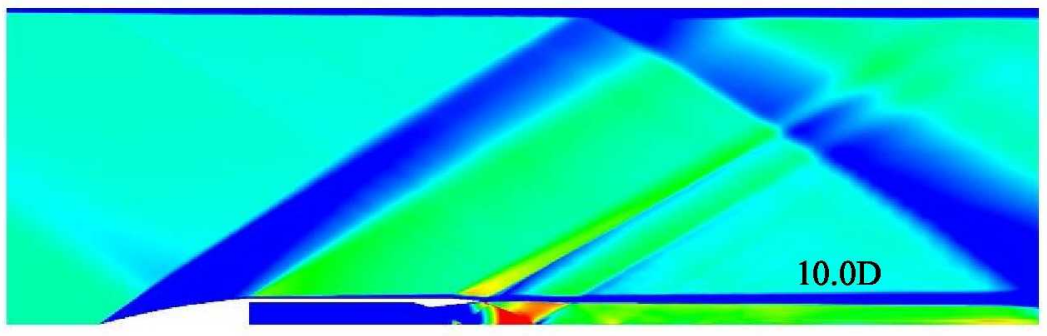

Figure 6(c). 3/4 Parabola: 10.0 diameter between nozzle exit and reflected shock wave at tunnel centerline.

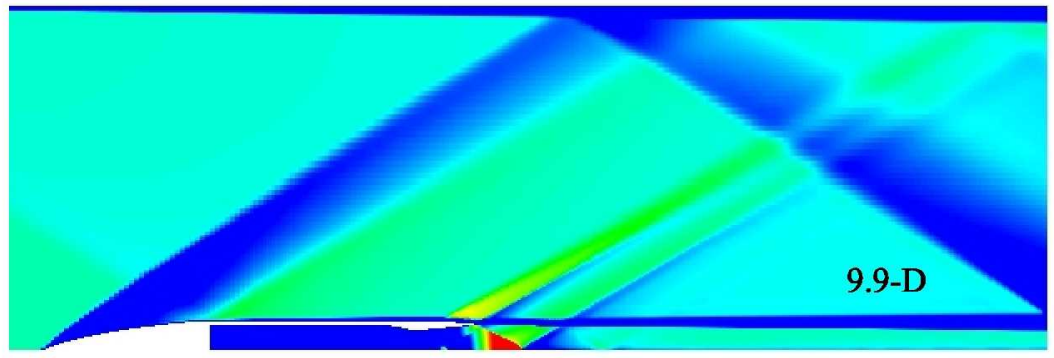

Figure 6(d). Von Karman Short: 9.9 diameter between nozzle exit and reflected shock wave at tunnel centerline. 


\section{Design}

This wind tunnel model was designed to operate across a variety of wind tunnel Mach numbers, nozzle pressure ratios, and simulated altitudes. Design Mach numbers could vary from 1.4 to 3.0. NPR could vary from 6 to 12, and intended altitudes were $30,000 \mathrm{ft}$ ( $4.36 \mathrm{psia}$ ) to $50,000 \mathrm{ft}$ (1.68 psia).

The model design was based on the 1 in. outer diameter, as was shown in Fig. 4. The final length from the nosecone to the nozzle exit was 9 in. Both nosecone and nozzle were attached with fine pitched threaded connections. The support strut was $3 / 8$ in. in diameter and contained nine passages to supply the needed airflow. Air supply lines were $1 / 4 \mathrm{in}$. diameter, and the passages supply 90 psia of pressure to achieve 20 psia at the nozzle inlet, for test conditions at simulated $50,000 \mathrm{ft}$ altitude. To accommodate future larger nozzles and testing at lower altitudes, the maximum design pressure at the nozzle inlet is 52 psia. Choked orifice holes were needed at the top of the strut supply lines to obtain pressure and flow upstream of choked test nozzles. Orifice holes were 0.210 in. diameter. Air was supplied to the bottom of the strut

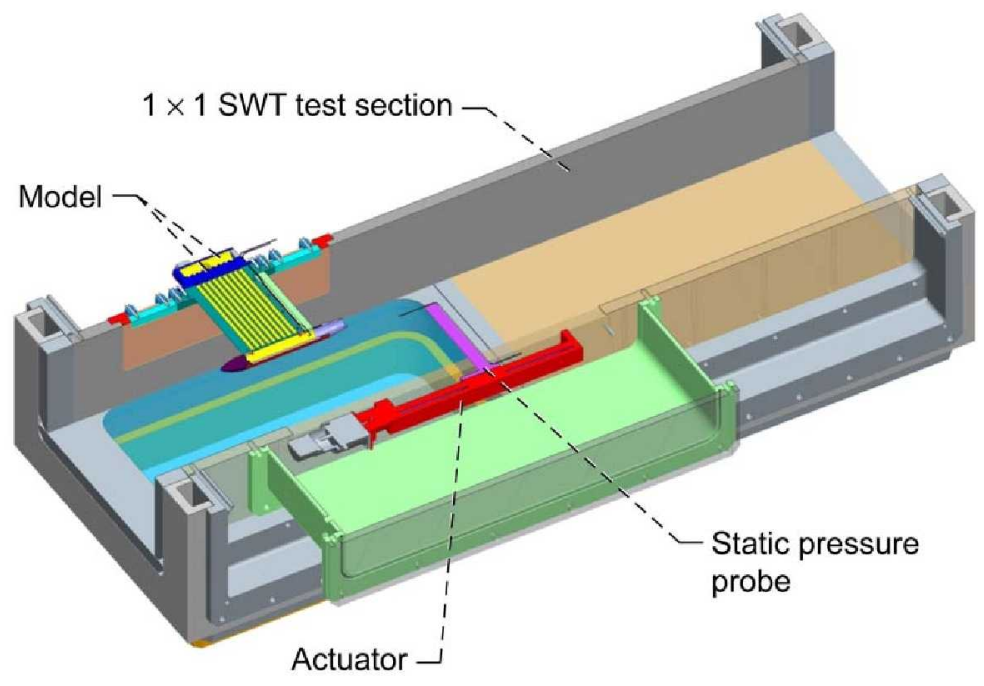

Figure 7. Wind Tunnel Model Cross Section as installed in the $1 \times 1$ SWT test section. through a lower plenum by pressurized air systems at the $1 \times 1 \mathrm{SWT}$. High pressure air was provided by the facility $450 \mathrm{psig}$ supply system. This system was designed to provide NPR settings within 1 percent of the set point.

The location of the model in the $1 \times 1$ SWT was determined by a shock wave pattern in the tunnel. This shock wave was generated by a small step in the tunnel wall located at the end of the interchangeable wind tunnel throat blocks, which wereused to set tunnel Mach number. This tunnel shock reflection was located so as not to interfere with the nozzle plume, in a similar fashion to the nosecone shock, (Fig. 7).

The location of the strut and model was designed to move forward and aft in the wind tunnel test section. This was accomplished with a slot, allowing 6 in. of overall travel. In this manner the rig location could be modified to avoid unforeseen wind tunnel flow effects or shock wave reflections. The design also included capability for testing of exhaust nozzle pairs, simulating multiengine aircraft configurations. Two strut assemblies could be installed at two specified distance increments, (Fig. 8). The first increment was a spacing of one nozzle diameter, center to center (touching), and the second increment was three nozzle diameters. Both struts were supplied by a common air manifold to provide matched test conditions.
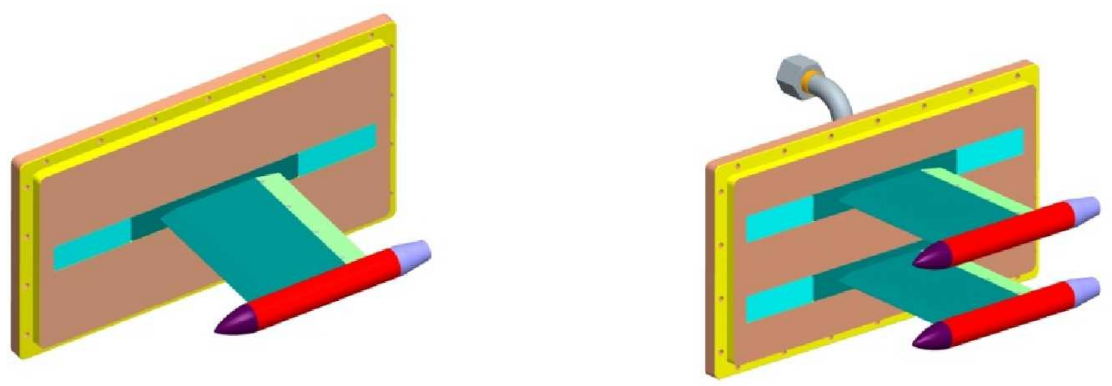

Figure 8. Single Nozzle and Nozzle Pair Installation. 


\section{Instrumentation and Data Systems}

Instrumentation was located internally to measure nozzle pressure ratio, and was limited to one total pressure probe upstream of the test nozzle, located on centerline, and one static pressure tap on the lower wall. An external static pressure probe was designed to survey near field static pressure profiles at one nozzle diameter above the rig centerline, also in Fig. 7. The probe had a travel of 10 in. to capture pressure profiles starting from the nozzle exit and extending back to where the plume interacts with the tunnel wall shock reflection. Two static pressure probes were built based on Pinckney, ${ }^{5}$ both a conventional and a short design. The conventional design, Fig. 9 , had limitations where the static pressure measurements are not in the same flow environment as the probe tip. The short probe design, (Fig. 10) allowed for a shorter probe with less sensitivity to angle of attack. These probes were mounted on a 3/8 in. thick airfoil strut, allowing 5.625 in. of probe length between the static pressure holes and the airfoil support. Actuation of the probe was provided by a sliding actuator with stepper motor control. The actuator was mounted outside the tunnel, in a sealed enclosure, and the airfoil support extended through a slot in the tunnel wall.

This model was placed between two transparent sidewalls in the $1 \times 1$ SWT for Schlieren photography and comparison to Mach number contours generated by CFD analysis. Placement of the model in the $1 \times 1$ SWT was determined by collecting Schlieren images with an empty test section. Figure 11 shows a Schlieren image from an empty test section. Two shock wave patterns were present in an empty test section. These shock waves were traced back to a joint in the wind tunnel wall at the end of the "Mach block", which provided an interchangeable convergent-divergent contour to set wind tunnel Mach number. These images were analyzed to determine the shock wave angle of $29.4^{\circ}$. If the model nosecone was placed at the intersection of the shock waves, then the reflected shocks from the "Mach block" would not reflect back to the wind tunnel centerline until 21.29 in. downstream of the nose cone. This provided adequate space to study the nozzle plume shock structure without interference from reflected shock waves.

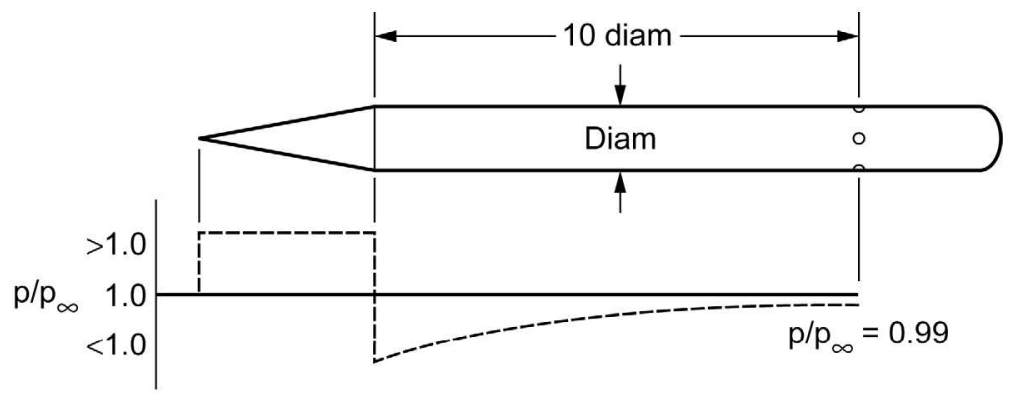

Figure 9. Conventional Static Pressure Probe. ${ }^{5}$

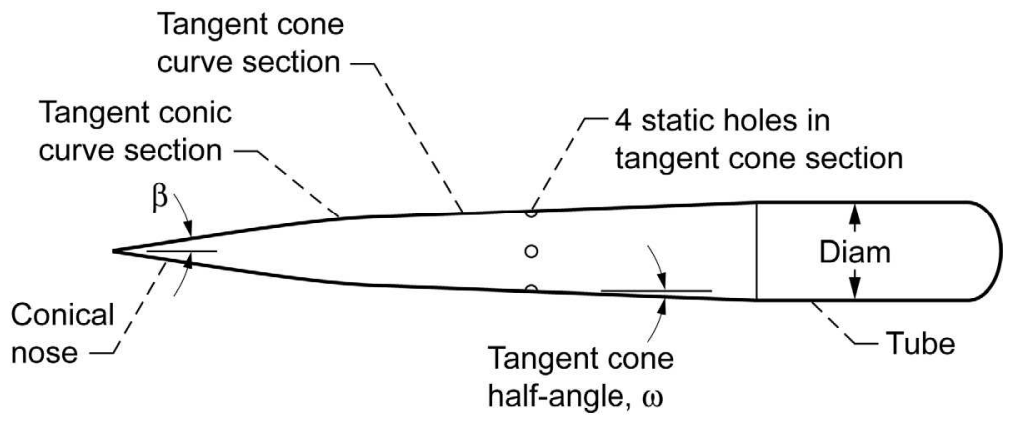

Figure 10. Short Static Pressure Probe Design. 5 


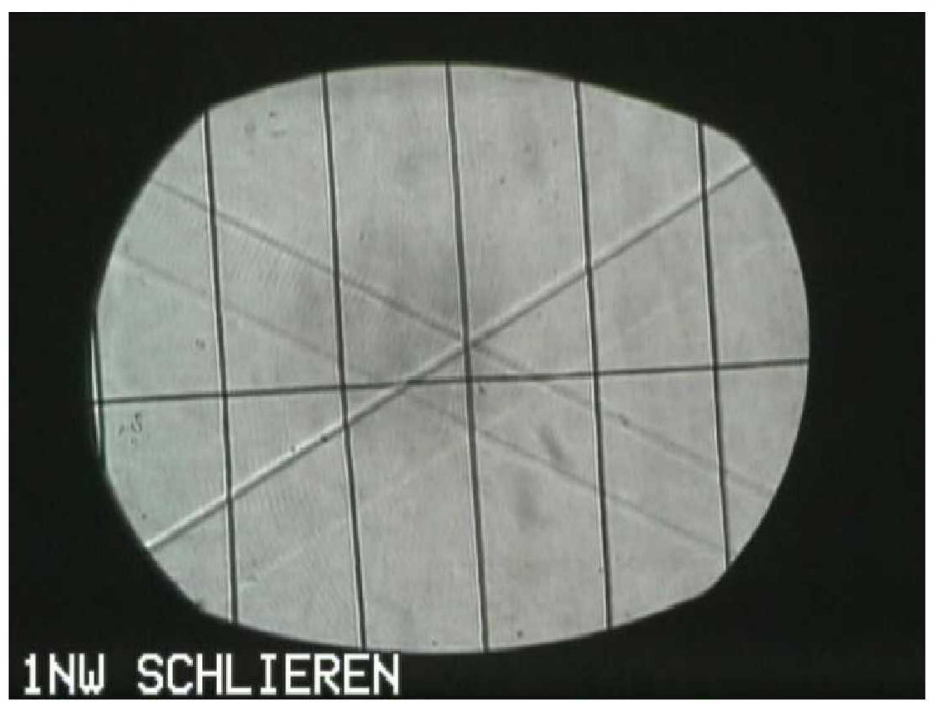

Figure 11. Schlieren image from empty test section.

\section{Concluding Remarks}

Analysis was conducted to design new capability for the $1 \times 1$ SWT. This new capability will provide a test rig to study exhaust nozzle plume effects on sonic boom. Critical capabilities of this rig include the ability to test interchangeable nozzles with a 1 in. outer diameter. Nozzle pressure ratios range from 6 to 12, and Mach number capability ranges from 1.3 to 3.0 .

Analysis was performed to size the nozzle test rig and avoid reflected shock waves from wind tunnel walls. Studies included alternative nosecone designs to determine their effect on the reflected shock waves. Schlieren images from an empty test section were analyzed to determine proper placement in the wind tunnel.

Plans include collection of static pressure profiles at one diameter above the tunnel centerline and Schlieren images from exhaust nozzle plume effects.

\section{Acknowledgments}

The author recognizes the contributions of Harold Kingsberg, from Case Western Reserve University, who performed significant analysis supporting this design and test. In addition, Martin Silverman, John Jones and Warren Holt provided design and fabrication of the wind tunnel model and support systems. Facility support was provided by Scott Smrdel.

\section{References}

${ }^{1}$ Putnam, L. and Capone, F.: Experimental Determination of Equivalent Solid Bodies to Represent Jets Exhausting into a Mach 2.20 External Stream, NASA TN-D-5553.

${ }^{2}$ Castner, R. S.: Analysis of Plume Effects on Sonic Boom Signature for Isolated Nozzle Configurations, NASA/TM-2008215414.

${ }^{3}$ Soeder, R., Stark. D., Leone, J., and Henry, M.: NASA Glenn 1- by 1- Foot Supersonic Wind Tunnel User Manual, NASA/TM-1999-208478.

${ }^{4}$ Seiff, A. and Sandahl, C.: The Effect of Nose Shape on the Drag of Bodies of Revolution at Zero Angle of Attack, NASA RM-A51J25.

${ }^{5}$ Pinckney, S. Z.: A Short Static Pressure Probe Design for Supersonic Flow, NASA TN D-7978.

6"Nose Cone Design," Wikipedia, 2009. 